\title{
Evaluation - The Cinderella Science of ICT in Health
}

\author{
M. Rigby \\ Centre for Health Planning and Management, Keele University, Keele, Staffordshire, United Kingdom
}

\begin{abstract}
Summary
Objectives: Information systems are expensive to create, and consume resources in their operation. They are justified in order to achievec learly defined objectives in health senice quality and efficiency. To ensuret that these objectives are being met, and in order to build up an evidence-base to support well focused policies, systems, and practice, evaluation would seem to be fullyjustified and indeed essential. However, there are major factors jeopardising good evaluation pradice, ranging from reluctance to commit resources or expose decisions to scutiny, through to lack of appreciation of the full range of dimensions which should be studied. This paper seeks to create fuller appreciation of theissues and theirimportance.

Methods: Experiential and literature reviews fom the basis of an exposition of principles, methods, and key current activities. Results: A summary has been produced of the key challenges to health ICT evaluation, and its adverse comparison with other sectors. An explanation of the viewpoints and levels of health information evaluation is followed by a shorthistory of principal milestones, current scientific methodology activity, and key collaborative activities.

Condusion: The need for a stronger commitment to health ICT evaluation is demonstrated if the application of health informatics systems is to receive due recognition as scientifically and empirically justified. Commitment of resources and scientific endeavour are needed, and thus the recent Declaration of Innsbruck, arising out of an event sponsored by the European Science Foundation, is timely and fullyjustified.

Haux R, Kullikowski C, editors. IMIA Yearbook of Medical Informatics 2006. Methods Inf Med 2006; 45 Suppl 1: S114-20.

\section{Keywords}

Evaluation, information systems
\end{abstract}

\section{Introduction}

It is a well known aphorism that people learn from experience. In practice the same holds true for organisations, if they have any form of corporate intelligence system. But "learning from experience" is a haphazard and anecdotal concept. However, it does have a scientific manifestation, namely evaluation. Primarily, this involves the objective measurement of processes and outcomes against expectations, with the intention of identifying strengths and successes, whilst finding means of addressing and improving weaknesses or even failures. Thus it would seem selfevident that evaluation should be a strong component of the health informatics portfolio - both in academic settings and in practical applied ones in healthcare organisations. Unfortunately, this is seldom the case.

\section{The Challenges to Evaluation}

Given that it would appear so self-evidently logical and important to check that what was intended to happen is indeed happening, but that this process seldom systematically takes place, it is essential first of all to understand the challenges against evaluation. What are the arguments that effectively legitimise continuing to make the same mistakes, and otherwise to "live in the dark"? An anthology of reasons has been published
[1], but there are a number of very different dimensions.

Diversion of Resources: Resources for health informatics investment are always inadequate against expectations. Resources have to be fought for. Thus the opportunity cost of committing human and other resources to evaluation studies is seen as too great because it diverts those resources from potential further system developments.

Loss of Reputation: Health informatics projects are high profile. Organisations and individuals will have had to argue both for the investment itself, and for the particular design and implementation adopted. If evaluation shows there are lessons to be learned, scapegoats may be sought, and protagonists blamed. Innovators are particularly reluctant to admit flaws in their vision, or even to accommodate alternative approaches [2].

Investment Capital Probity: Health informatics initiatives normally are not cheap. Whether public or private money is involved, the investors or their agents may not be happy if they believe that less than full value was obtained in terms of results for the investment. Future business relationships may be jeopardised, and for public funds there may be political repercussions.

It's All Too Complicated: Health informatics systems are implemented in a dynamic world. Systems, organisational frameworks, and user requirements are all constantly developing, at loggerheads with the project management 
principle of creating stable space in which to make progress. Users may have unrealistic expectations; they may also not be briefed in the changes in working practice and working methods created by moving from paper-based systems (or from earlier generation electronic systems). The situation is inevitably multifactorial, and isolating out extraneous changes and individual causal effects is difficult.

Banana Skin Republic: In short, there are too many banana skins to slip on. IT systems have a perceived track record of overrunning, over-costing, and under performing, whilst prior to project commencement the exponents may well have "talked up" the benefits and "talked down" the challenges. So why bother with evaluation when it will only show gloomy results?

\section{Robustness in Other Sectors}

Clearly, this is a pessimistic picture, and one which must not be allowed to prevail. Many other areas of applied academic study show a mixture of good news and positive learning points from problems identified. This ranges from macro-economic and public finance analyses, where there is never any suggestion (outside totalitarian regimes) that such studies should be stopped in case they show bad news, whilst pharmacology would never be allowed to turn a blind eye to adverse outcomes, whether expected or unexpected. Possibly the classic model for learning from outcomes is the civil aviation industry, where there is international accord that immediate investigative and preventive action should be taken if there is any hint of an adverse outcome from a technological or human application.

This last analogy is not excessive there is clear expression of the concept that "Bad Health Informatics Can Kill" (3), and another study has shown a list of adverse effects of clinical IT systems (4). But more importantly, good health informatics evaluation can further the cause for modernisation through electronic data capture and processing. At present health informatics is built far too much on visions $(5,6,7)$, or on anthologies of past evidence (8), with far too few examples of proven benefits from recent evaluations strengthening and deepening investment in particular application areas.

\section{Aspects of Evaluation}

One of the obvious challenges is due to the fact that evaluation is far from a homogenous, one-size-fits-all process. Put very broadly, a number of different key viewpoints or dimensions can be identified, and secondly three levels of depth.

The dimensions can be summarised as:

\section{Performance Evaluation}

This is the review of whether the informatics system discharges the technical specification. This can be from the viewpoint of discharging the detailed specification, in terms of processes, data items and their presentation, and so on. But in a more integrated way, it will seek to assess whether the core business support processes of the system are discharged. This is important given that a sound computer application should not merely automate paper processes, or replicate an earlier computer system, but should seek to identify and discharge effectively the core functions, such as transmitting pathology requests to the laboratory and presenting the results back to the requesting clinician, or undertaking a fi- nancial management process. The specification check type of evaluation will be aimed primarily at assessing whether any rectifications are needed, whilst the deeper approach will be much more focused on organisational learning and discovering whether modernised methods of working are achieving the core business objective. Only by learning from implementations can knowledge be furthered as to how business processes and both patient and organisational management can be furthered.

The main problem with this aspect of evaluation is that it is the area most seen as challenging the competence of those who have defined the requirements, the decisions of those who have authorised the procurement, and the proficiency of the supplier. In extremis these problems may truly arise, but by far the greater and nor mally more important learning from this aspect of evaluation is that of learning about the techniques of process specification, the performance of different technology and software components under different combinations of operational circumstances, and the visioning of process redesign.

\section{UserViews}

In terms of success or failure of a system, in the spectrum between efficiency on the one hand and costliness on the other, this is the most important dimension. It is also the one aspect which is most frequently overlooked. Too often users are taken for granted, and system experts forget that the prime focus of expertise of end users of health systems is elsewhere - for instance, in nursing or medicine. Secondly, accommodating the individualised needs of users in the specification process, and education and training of users in the implementation process, are both expensive activities. 
In an era of constrained resources (both public investment levels and private supplier profit margins), these are areas where it is tempting to trim expenditure, and consequently at the time of specification and of preparing the implementation plan, typical end users frequently are not represented in the core decision making processes.

\section{Organisational View}

Once an organisation has invested - usually heavily - in a health informatics application, the prime drive is to ensure that it is seen to work satisfactorily. If technicians or users report serious problems they naturally have to be fixed. However, any evaluation study which shows that the organisation appears to have acquired a less than optimal solution is unwelcome as an apparent questioning of organisational competence at policy or procurement levels. This unfortunate interpretation may be applied even if the lessons learned from the evaluation are as a result of potential new opportunities for improvement as a result of user or corporate learning from an initial period of successful implementation. Thus there is a strong corporate drive to undertake internal checks to ensure that there are no problems causing technical or user friction but to deal with these privately and discreetly, whilst at the same time seeking to avoid more formal evaluations with the perceived corporate risk of the possibility of finding uncomplimentary results.

At the same time as addressing the principle stakeholder views, it is also possible to identify three different depths (broadly matched to time-scales) to which the evaluative study may be undertaken [9]. These are again summarised below.

\section{Tednnical Fundioning}

It is comparatively easy to undertake the first level of evaluation, namely whether the technical functions are achieved. However, the word "comparatively" is the key one. As health informatics applications become increasingly complex, it is now increasingly difficult, tending to the impossible, to check systematically every combination of inter relational functioning under every different combination of circumstances and data values. Thus the evaluation of function cannot any longer be considered as absolute except with the simplest of systems

\section{ResultantEffects}

Every health informatics application has a deeper functional purpose than merely collecting the specified data and undertaking the related computational processes. The system is there to support a business process, and there is an iterative pattern of change caused by the relationship between the structuring of processes to enable computerisation, the standardisation of operations to ensure that the data flow to and from the system appropriately, and the execution of the core business objectives by the healthcare staff, whether this is a clinical support system, financial, or other business management. Thus evaluation should look for results in terms of increased quality, efficiency, or reliability of the supporting business process.

These results may be conflicting, requiring an overall balancing judgment. For instance, quality of prescribing and speed of dispensing may increase with a prescribing support system, yet the system itself may have operating costs greater than the previous paper systems, thus compromising the operational budget. Telemedicine may save neither health system costs nor professional time, yet deliver a better quality and more convenient form of care [10].

\section{Deeper Outcomes}

Once a health informatics system is installed and in regular use, it may have deeper consequences, both anticipated or unanticipated. Only a matching evaluation study will show whether these are beneficial effects, such as improving efficiency, quality, or practitioner satisfaction on the one hand, or are perverse effects such as increasing staff "technophobia" leading to staff loss, or restricting appropriate special circumstance "off protocol" prescribing or procedures. Rigid diagnostic coding systems may either make standardised clinical data about a patient more readily available in more accurate form, or may have adverse effects such as diagnosis delay because uncertainty cannot be accommodated, or diagnosis creep to ensure workloads are not under-represented.

These two dimensions of evaluation can be seen to interlink. Table 1 shows their inter-relationship, and the different evaluative subjects possible in each of the dimensional intersecting cells.

\section{A Short History of Evaluation}

Though evaluation is under-rated and under-invested, there have been important advocates over time. This next section gives a mere snapshot of some of the more important contributions. In the United States, some of the earliest modern evaluations which show user views were the result of work by Anderson, Aydin and Jay [11], and the colleagues who contributed to their work. These studies showed the importance of evaluation in that it gave some un- 
Table 1 The Inter-relationship of the Two Axes of Ecaluation

\begin{tabular}{|c|c|c|c|}
\hline & Does it work? & With what Results? & With what Outcomes? \\
\hline Technical & $\begin{array}{l}\text { Technical performance, } \\
\text { speed, etc. satisfactory } \\
\text { Reliability/availability }\end{array}$ & $\begin{array}{l}\text { Technology proven in use } \\
\text { Process specifications } \\
\text { proven in use }\end{array}$ & $\begin{array}{l}\text { Further uptake/ roll out } \\
\text { Positive (negative) image }\end{array}$ \\
\hline User & $\begin{array}{l}\text { Ease of use/ compliance } \\
\text { Trust } \\
\text { Reliability of function }\end{array}$ & $\begin{array}{l}\text { Time saved (lost) } \\
\text { Better (worse) working } \\
\text { context } \\
\text { Better (worse) quality } \\
\text { delivered }\end{array}$ & $\begin{array}{l}\text { Job satisfaction } \\
\text { (dissatisfaction) } \\
\text { Professionalism gain (loss) }\end{array}$ \\
\hline Organisation & $\begin{array}{l}\text { Specification met } \\
\text { Senvice delivered }\end{array}$ & $\begin{array}{l}\text { Efficiency gains (losses) } \\
\text { Throughput changes }\end{array}$ & $\begin{array}{l}\text { Competitive Positioning } \\
\text { Recruitment effects } \\
\text { Referral effects }\end{array}$ \\
\hline
\end{tabular}

expected results, such as limited clinician compliance and very restricted use of available functionality. The subsequent European equivalent focus was in Maastricht and a key publication was by Van Gennip and Talmon [12]. Both texts contained seminal papers both on methodologies as well as on findings. Both these works have an appropriate heavy focus on the user view. For reasons already intimated, published scientific evaluations of the technological aspects are less common, but have significant points to make when they are undertaken. The installation-focussed publication by Hasselbring and his colleagues is a case in point [13]. Meanwhile, at the other end of the spectrum one institute with a reputation for looking at the effect of modern automation of data handling on work practice is the Norwegian Work Research Institute. Though this is a generic institute working on many aspects of work under the effect of modern methods, within this Aas has focused on the effects of the application of Information and Communication Technologies (ICT) within health. This has lead to a significant number of health sector studies (such as [14-18]).

\section{The Development of Evalua- tion Networks}

However, important though individual studies, and the work of individual institutions, can be in such a vast and under-developed field, much greater strength can come out of collaborative networks. One of the first was initiated by Van Gennip and Talmon and was the Assessment of Information Technology in Medicine (ATIM) group, funded through the European Commission's Third Framework Programme in 1993 to make an inventory of evaluation methods, and which resulted in the publication already cited [12]. Subsequently, this project evolved into the
Validation of Telematics Applications in Medicine (VATAM) programme.

A more recent initiative emerged from UMIT, the privately funded University of Health Sciences, Medical Informatics and Technology, located in Innsbruck, Austria. There Ammenwerth has developed a focus on evaluation studies, and obtained from the European Science Foundation funding in 2003 for an international Exploratory Workshop on Evaluation of Health Informatics Systems (termed HIS-EVAL). This led to development of a number of concepts and to the establishment of the Declaration of Innsbruck - see below. The final report is available from the European Science Foundation website [19], as well as from other publications [20]. Another important enduring product of the UMIT Exploratory Workshop is the establishment of the Health Informatics Systems Evaluation (HISEVAL) network, based on the workshop membership.

A second, and related, network is that of the European Federation of Medial Informatics (EFMI), through its Working Group for Assessment of Health Information Systems. Also led by Ammenwerth, this network has its own web site [21]. The equivalent global group is that of the International Medical Informatics Association (IMIA), whose Technology Assessment \& Quality Development in Health Informatics (Working Group 15) is also led from Europe by Talmon, a HIS-EVAL and VATAM member [22].

\section{Development of Scientific Techniques}

An important issue emerging from these more recent collaborative moves towards evaluation of health informatics systems is the need to develop the scien- 
tific methods of evaluation. This has identified a number of key issues.

\section{Formative or Summative?}

One key issue is the balance between formative or summative evaluation. The natural approach of many external organisations and sponsors is to seek a Summative evaluation - namely to determine at the end of an implementation process how well the system is functioning, and what are its effects. This may fit the investor's or organisational developer's desire to know the yield for the investment. It may produce important results, including cost and benefit effects, but in terms of taking corrective action it is largely too late to benefit the study site itself, as it is axiomatic that the cost of changing an application increases exponentially in relation to its length and depth of use. By contrast, formative evaluation works alongside the design and implementation process, assessing the effects and appropriateness of each stage. This active intervention approach to evaluation is far more beneficial to the study site as it provides feedback which enables action in an immediate way. However, its very interventionist nature means that the outcomes of the original approach can no longer be assessed, as in research terms the site has been "contaminated". Thus the enduring scientific learning is of a very different nature.

\section{Funcional or Behavioural Analysis}

A second aspect of the debate as to appropriate evaluation approaches concerns whether the technical system is the most important focus of evaluation, or the behavioural aspect, considering the behaviour both of the human users and of the organisation. Early work by Grémy and Bonnin highlighted this well [23], and the first author has subsequently returned to the theme [24]. Whilst it is an important principle for scientists to evaluate the components and products with which they work, healthcare is very much a collaborative activity for the benefit of society, and thus it is self evidently important also to study the human and societal effects and outcomes.

\section{Economicand Quality Effects}

Whilst it is apposite to evaluate how technology works, and how its users behave, these are themselves both narrow views. Deeper evaluation of health informatics systems needs to look at the consequent effects.

One such consequent effect is the economic one. Health informatics systems will generate new costs, and in particular maintenance and ongoing training costs are frequently underestimated. On the other hand they will often generate cost savings - either directly by replacing slower manual processes, or indirectly through facilitating more efficient working. However, because the implementation of an information system itself changes the organisational processes and working patterns, such financial and economic evaluations can be quite difficult in their requirement to factor out the concurrent internal and external changes.

Turning secondly to quality, the intention to improve quality is often a major driver for investment in health information systems. Not least the United States institute of Medicine has shown this as an aspirational issue both in theory from their vision of the Computer Based Patient Record [5], and more recently as a very practical approach to addressing proven quality challenges
[25]. At the individual application level, systems are frequently and validly intended to improve quality by making better information available, reducing the risk of inappropriate actions, and increasing the efficiency and corporate knowledge of the organisation. However, demonstrating through evaluation studies the achievement of this, factoring out other concurrent changes, and also assessing quality improvements achieved against the benchmark of what was intended, can both be difficult calculations.

For these reasons, the development of these scientific techniques of evaluation is particularly important. This was one of the motivations of the ATIM and VATIM networks, and was specifically an intention of the European Science Foundation Workshop and subsequent HIS-EVAL network [19]. The existing literature covers a broad spectrum, with the work of Friedman and Wyatt [26] in particular focusing on conceptual frameworks such as randomised trial and similar approaches, whilst BeuscartZephyr based at the EVALAB in Lille has undertaken important work at the usability and interaction end of the spectrum (for example 27-30). However, until research funding bodies can recognise the importance of evaluation, and in particular of developing a proven range of evaluation tools appropriate to circumstances, the literature on scientific techniques on evaluation will continue to remain thin.

Finally, while evaluation from development and test sites is vitally important, it is not the complete story, and indeed can be misleading, as such sites have special characteristics which are likely to facilitate good results. Evaluating the effects when applications are move on into the real world with no special support is the only means of generating a generalisable view of the results in practice [31]. 
Evaluation - The Cinderella Science of ICT in Health

\section{Case Studies}

In the wider field of health policy and management, case studies are seen as being an important tool, not least for two particular reasons. One is that they give a critical review of the totality of the environment and driving forces for any particular initiative, and thus this can be assessed in context, and the lessons and learning points translated as appropriate to other settings and circumstances. The second reason for their importance is that they can take into account changing environmental circumstances. Thus case studies can provide an evaluation tool of a qualitative nature, rather than one of a purely quantitative type. Apart from individual case studies published in scientific journals, case studies feature largely in a number of specific texts $[32,33,34]$.

\section{Compilations of Studies}

An important tool to assist those seeking to apply an evaluation methodology, or indeed to undertake first-level thinking as to the issues which might be important, is the compilation of case studies. Such compilations will enable users to identify similar settings, similar systems, or the range of potential techniques, which might be applicable to their own circumstances. There have been recent developments in publication of such compendia, of which that compiled by UMIT [35], and the compendium by Ammenwerth and de Keizer [36]. are recent significant ones. Subsequently, a four nation team has published the detailed results of a Delphi study into factors influencing success and failure of health informatics systems, drawing on wide participant experience [37]. The lead author of this study has also just published a handbook of evaluation methods for health informatics [38].

\section{Dedaration of Innsbrudk}

However, the most important single milestone in the development of an evaluation culture in health informatics has been the publication of the Declaration of Innsbruck. This was one of the principle products of the aforementioned European Science Foundation Workshop, and has subsequently been published in the International Journal of Medical Informatics [20], and subsequently discussed [39]. This sets out definitions of "system" and "evaluation", recognises both the benefits and the intellectual and resource challenges of evaluation, then moves on to twelve key recommendations, which are that:

1. Evaluation should be seen as an ethical imperative.

2. Evaluation should be sufficiently funded.

3. Evaluators should be free from pressure.

4. Evaluation studies should be grounded on scientific theory and rigorous approaches.

5. Evaluation methods should be selected with an open mind.

6. Reports on methodological and methodical studies should be encouraged.

7. Guidelines for good evaluation practice should be made available.

8. Terms, concept and guidelines for reporting on results of ICT assessment studies should be developed.

9. Evaluation should be promoted by centres of excellence.

10. Evaluation networks should be established.

11. An open access repository about evaluation studies should be established.
12. Appreciation of methods of evaluation should be part of health informatics curricula.

Thus it can be seen that the Declaration of Innsbruck is both an achievement in consensus, yet at the same time is intentionally a challenging starting point, but an essential one if health informatics systems are to be ensured as beneficial and not harmful [40]. The full text of the Declaration of Innsbruck is published on pages 121-123 in this volume.

\section{Condusion}

This review paper has sought to give a modest appraisal of the key issues in the need to bring evaluation to the forefront, and to develop techniques, whilst citing a selection of the key literature. However, the Declaration of Innsbruck fluently identifies both the challenges and the necessary next steps. If health informatics is to mature in order to claim its place as a scientific health discipline, it needs both the techniques and the impartially and regularly applied self-reflection of evaluation studies if it is to demonstrate its objectivity and maturity. Without deep evaluation, the promotion of health informatics will ever be open to criticism as being uninformed enthusiasm and the marketing of products and novelties. Adequately funded evaluation, based on proven sound techniques, is the means of moving forward to a credible discipline alongside many others available in the health domain. The Declaration of Innsbruck provides a key marker at a critical stage along this route, as to how the development of evaluation as key tool should proceed. 


\section{References}

1. Rigby M. Evaluation: 16Powerful Reasons Why Not to Do It - And 6 Over-Riding Imperatives. In: Patel V, Rogers R, Haux R, editors. Medinfo 2001: Proceedings of the $10^{\text {th }}$ World Congress on Medical Informatics. Amsterdam: IOS Press; 2001. p. 1198-202.

2. Guist SHF, Rigby MJ. The Rise and Fall of the Innovator. In: Lun KC, Degoulet P, Piemme TE, Rienhoff O. Medinfo 92 - Proceedings of the Seventh World Congress on Medical Informatics, Geneva Palexpo, Switzerland, 6-10 September 1992, Amsterdarm: Elsevier Science Publications BV, North-Holland; 1992.

3. http://iig.umit.at/efmi/ (Bad Health Informatics page) (accessed 21.11.2005)

4. Ash J, Coiera E, Berg M. Some Unintended Consequences of Information Technology in Health Care: The Nature of Patient Care Information System-related Errors. J AmMed Inform Assoc 2004; (11): 104-12.

5. Institute of Medicine (R. Dick, E. Steen, editors) The Computer Based Patient Record - An Essential Technology for Healthcare. Washington DC: National Academy Press; 1991.

6. Department of Health. Information for Health: An Information Strategy for the Modern NHS; Department of Health, London, 1998.

7. Department of Health. Delivering 21st Century IT Support for the NHS, London: Department of Health; 2004.

8. National Health Information Management Advisory Council. Health Online. A Health Information Action Plan for Australia. Canberra: Department of Health and Aged Care; 1999.

9. Rigby M. Health Informatics as a Tool to Improve Quality in Non-acute Care - New Opportunities and a Matching Need for a New Evaluation Paradigm; Int J Med Inform 1999 (56): 141-50.

10. Malmquist G, Hansson U, Qvarnström A Carlsson G. Health Practice by Remote Expert: a Case Study from Sweden. In: Rigby M, Roberts R, Thick M, editors. Taking Health Telematics into the $21^{\text {st }}$. Century. Abingdon: Radcliffe Medical Press; 2000.

11. Anderson JG, Aydin CE, Jay SJ, editors. Evaluating Health Care Information Systems: Methods and Applications. Thousand Oaks, CA: Sage; 1994.

12. van Gennip EMSJ, Talmon JL, editors. Assessment and Evaluation of Information Technologies in Medicine. Amsterdam: IOS Press; 1995.

13. Hasselbring W, Peterson R, Smits M, Spanjers R.
Strategic Information Management for a Dutch University Hospital. In: Hasman A, Blobel B, Dudeck D, Engelbrecht R, Gell G, Prokosch H-U, editors. Medical Infobahn for Europe: Proceedings of MIE2000 and GMDS2000. Amsterdam: IOS Press; 2000. p. 969-73.

14. Aas IH. Telemedical work and co-operation, J Telemed Telecare 2001; 7(4): 212-8.

15. Aas IH. A qualitative study of the organizational consequences of telemedicine. J Telemed Telecare 2001;7(1): 18-26.

16. Aas IH. Changes in the job situation due to telemedicine. J Telemed Telecare 2002; 8: 41-7.

17. Aas IH. Organizing for remote consultations in health care - the production process. Behaviour and Information Technology 2003; 22: 91-100.

18. Aas IH. Organizational cooperation in teleradiology. J Telemed Telecare 2005: 11: 45-50.

19. www.esf.org/generic/1651/EW0212Report.pdf (accessed 22.11.2005).

20. Ammenwerth E, Brender J, Nykänen P, Prokosch H-U, Rigby M, Talmon J, et al. Visions and strategies to improve evaluation of health information systems: Reflections and lessons based on the HIS-EVAL workshop in Innsbruck. Int J Med Inform 2004; 73(6):479-91.

21. iig.umit.at/efmi/(accessed 21.11.05).

22. www.imia.org (follow Working Groups link) (accessed 21.11.2005)

23. Grémy F, Bonnin M. Evaluation of Automatic Health Information Systems - What and How? In: van Gennip EMSJ, Talmon JL, editors. Assessment and Evaluation of Information Technologies in Medicine. Amsterdam: IOS Press; 1995.

24. Grémy F. Hardware, software, peopleware, subjectivity. A philosophical promenade. Methods Inf Med.2005; 44(3): 352-8.

25. Institute of Medicine. Crossing the Quality Chasm: a new health system for the $21^{\text {st }}$. Century. Washington DC: National Academy Press; 2001.

26. Friedman CP, Wyatt J C. Evaluation Methods in Medical Informatics. New York: Springer; 1997.

27. Beuscart-Zephir MC, Brender J, Beuscart R, Menager-Depriester I. Cognitive evaluation: how to assess the usability of information technology in healthcare. Comp Methods Programs Biomed 1997; $54(1-2): 19-28$

28. Beuscart-Zephir MC, Anceaux F, Renard JM. Integrating users' activity analysis in the design and assessment of medical software applications: the example of anesthesia. Stud Health Technol Inform 2000; 77: 234-8.

29. Beuscart-Zephir MC, Menu H, Evrard F, Guerlinger
S, Watbled L, Anceaux F. Multidimensional evaluation of a Clinical Information System for anaesthesiology: quality management, usability, and performances. Stud Health Technol Inform 2003; 95: 649-54.

30. Beuscart-Zephir MC, Pelayo S, Degoulet P, Anceaux F, Guerlinger S, Meaux JJ. A usability study of CPOE's medication administration functions: impact on physician-nurse cooperation. Medinfo 2004;11(Pt 2): 1018-22.

31. Rigby M. Essential Prerequisites to the Safe and Effective Widespread Roll-out of E-Working in Healthcare. Int J Med Inform 2006; 75: 138-47.

32. Roger-France F, Noothoven van Goor J, StaehrJohansen K: Case-Based Telematic Systems Towards Equity in Health Care (Studies in Health Technology and Informatics Vol. 14). Amsterdam: IOS Press; 1994.

33. Lorenzi NM, Riley RT, Ball MJ, Douglas JV. Transforming Health Care Through InformationCase Studies. New York: Springer-Verlag; 1995.

34. Drazen EL, Metzger JB, Ritter JL, Schneider MK. Patient Care Infomration Systems - Successful design and Implementation. New York: SpringerVerlag; 1995.

35. evaldb.umit.at/ (accessed 22.11.2005).

36. Ammenwerth E, de Keizer N. An inventory of evaluation studies of information technology in health care trends in evaluation research 1982-2002. Methods Inf Med 2005; 44(1): 44-56.

37. Brender J, Ammenwerth E, Nykänen P, Talmon J. Factors Influencing Success and Failure of Health Informatics Systems - A Pilot Delphi Study; Methods Inf Med 2006; 45(1): 125-36.

38. Brender J. Handbook of Evaluation Methods for Health Informatics: Academic Press; 2006.

39. Talmon JL, Ammenwerth E. The declaration of Innsbruck: some reflections. Stud Health Technol Inform 2004; 110: 68-74.

40. Ammenwerth E, Shaw NT. Bad health informatics can kill-is evaluation the answer? Methods Inf Med 2005; 44 (1): 1-3.

\section{Correspondence to:}

Michael Rigby

Professor of Health Information Strategy

Centre for Health Planning and Management

Darwin Building

Keele University

Keele, Staffordshire, ST5 5BG

United Kingdom

E-mail: m.j.rigby@ hrm.keele.ac.uk 